\title{
ANÁLISE DOS MÉTODOS DE POSICIONAMENTO E DOS PARÂMETROS DEFINIDORES DA QUALIDADE DE UM LEVANTAMENTO BATIMÉTRICO
}

\author{
Analysis of positioning methods and quality parameters of a bathymetric survey
}

\author{
Laís Thie Hasuda Nakao ${ }^{1}$ \\ Cláudia Pereira Krueger ${ }^{1}$
}

${ }^{1}$ Universidade Federal do Paraná. Programa de Pós-Graduação em Ciências Geodésicas. Centro Politécnico - Jardim das Américas. Caixa Postal 19001, Curitiba-PR, Brasil. Email: laishasuda@gmail.com; cpkrueger64@gmail.com

\begin{abstract}
Resumo:
O método de posicionamento a ser empregado em um levantamento batimétrico algumas vezes é questionado, quanto a sua precisão horizontal e vertical. De forma geral, tem sido utilizado nesses levantamentos o posicionamento da embarcação por meio do GPS Diferencial (DGPS). Mediante consulta de literatura, poucas investigações no que concerne à precisão e acurácia destes métodos têm sido realizadas principalmente quando tais levantamentos ocorrem em reservatórios. Dessa forma, o presente trabalho teve como intuito verificar as precisões e acurácias para o posicionamento da embarcação por meio dos métodos DGPS, Posicionamento por Ponto Preciso (PPP) e de Posicionamento Relativo Cinemático (MPRC). Todos os resultados gerados neste trabalho foram inseridos em um Sistema de Informação Geográfica (SIG), no qual foi observado que o resultado mais preciso foi obtido pelo MPRC. No entanto, também é possível utilizar o serviço online do IBGE-PPP para processar os dados para o posicionamento da embarcação obtendo uma precisão inferior ao metro. Conclui-se que todos os métodos investigados para o posicionamento da embarcação atenderam as especificações da Resolução Conjunta ANEEL/ANA n ${ }^{\circ}$ 03, de 10 de agosto de 2010 (BRASIL, 2010). Contudo, é importante que o usuário atenda aos requisitos mínimos necessários para cada método de posicionamento.
\end{abstract}

Palavras-chave: ArcGIS, Precisão, IBGE-PPP, Reservatório de Capivari-Cachoeira.

\begin{abstract}
:
The positioning method to be employee in a bathymetric survey is questioned about the horizontal and vertical precisions. In a general way, the vessel positioning in hydrographic surveys has been determined through the Differential GPS (DGPS). Upon consulting the literature, it was observed that few investigations regarding to the precision and accuracy of these methods were done when such surveys occur in reservoirs. Therefore, the main objective of the present work is to perform precisions and accuracies analyzes regarding to positioning of the vessel, through the methods as DGPS, Precise Point Positioning (PPP) and Kinematic Relative Positioning (MPRC). All results were inserted into a Geographic Information System (GIS), in which it was observed that the
\end{abstract}


results were more precise for the MPRC. However, it was concluded that it is also possible to use the IBGE-PPP online service to process the positioning data of the geodetic marks and the vessel getting a precision lower than a meter. In conclusion, all methods investigated for positioning the vessel are in agreement with the specifications of the Resolution ANEEL/ANA $n^{\circ} 03$ of August $10^{\text {th }}, 2010$. Nevertheless, it is important to follow the minimum requirements for each positioning method.

Keywords: ArcGIS, Precision, IBGE-PPP, Reservatório de Capivari-Cachoeira.

\section{Introdução}

A construção de uma barragem e a formação do seu reservatório normalmente modificam as condições naturais do curso d'água. O levantamento batimétrico sistemático é uma necessidade para determinação da disponibilidade hídrica através das curvas cota $\mathrm{x}$ área $\mathrm{x}$ volume, verificação da forma do reservatório, do cone de dejeção de sedimentos, e diversas outras informações. Tais medições podem indicar ainda a qualidade ambiental das águas, bem como a flora e fauna que nele habitam (ANA, 2013).

No âmbito de ambientes epicontinentais, mais especificamente em reservatórios, existem diversos trabalhos quanto ao posicionamento em levantamento batimétrico, utilizando suas informações para análises de declividade, assoreamento, volume, entre outros. A partir da aplicação de Sistemas de Informação Geográfica (SIG) em reservatórios foram verificados trabalhos que envolvem análises espaciais da distribuição e classificação de compostos químicos, ictiofauna, geologia, e geração de modelos digitais do terreno a partir dos dados de cota, por exemplo.

$\mathrm{Na}$ Turquia foi realizado um estudo das mudanças batimétricas utilizando SIG, onde Ceylan et al. (2012), coletaram dados batimétricos através do RTK que posteriormente foram inseridos no software ArcGIS 9.2, no qual foi gerado um Modelo Digital de Elevação (MDE) e feitas análises integrando conjuntos de dados de qualidade de água e mapas de uso do solo. Apesar do grande volume de trabalhos realizados em reservatórios, não se obteve resposta a nível nacional e internacional, para análises com parâmetros, como número de satélites, PDOP e resolução das ambiguidades, que influenciam na qualidade de um levantamento batimétrico que estivessem associadas com o SIG. Mediante esta constatação, verifica-se a possiblidade de novos estudos em relação às análises espaciais das precisões dos diferentes métodos de posicionamento para um levantamento batimétrico em reservatórios.

Nesse contexto, o objetivo desta pesquisa foi analisar os métodos de posicionamento e os parâmetros definidores da qualidade do posicionamento da embarcação em levantamento batimétrico realizado no Reservatório de Capivari-Cachoeira (Figura 1), que está localizado na Rodovia BR-116 (trecho Curitiba: São Paulo), entre os municípios de Campina Grande do Sul e Bocaiúva do Sul, com coordenadas geográficas situadas a $25^{\circ} 07^{\prime}$ de Latitude Sul e $48^{\circ} 44^{\prime}$ de Longitude Oeste, a $50 \mathrm{~km}$ de Curitiba (Carvalho, 2009; COPEL, 2011). Possui uma área de aproximadamente $13 \mathrm{Km}^{2}$, volume de $179.000 .000 \mathrm{~m}^{3}$; e profundidade média de 14 metros e máxima de 43 metros (Carvalho, 2009; IAP, 2010; FCMC, 2014). 


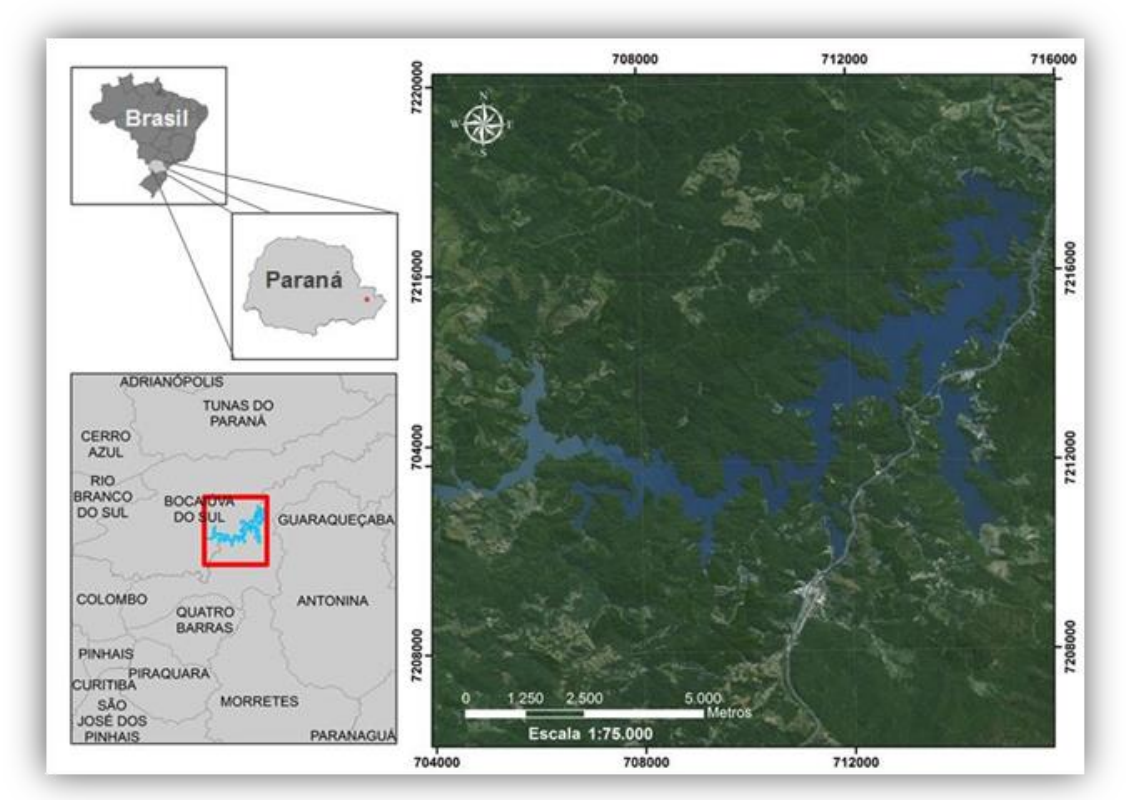

Figura 1: Localização do reservatório de Capivari-Cachoeira localizado no estado do Paraná. Coordenadas em metros, projeção UTM: Sistema de Referência SIRGAS 2000, zona 22S.

Fonte: Com base de dados de Bing Maps e SPU.

\section{Métodos De Posicionamento}

O posicionamento através do GPS diz respeito à determinação da posição de objetos em relação a um referencial e época específicos, podendo ser realizado a partir de diferentes técnicas e observáveis, as quais fornecem níveis de precisão que variam desde algumas dezenas de metros até poucos milímetros (Figura 2). Normalmente, é efetuado a partir da fase de batimento da onda portadora e/ou da pseudodistância. Devido à precisão da medida da fase da onda portadora ser da ordem de milímetros, ela é a observável indispensável na obtenção de posicionamentos que requerem melhor precisão. A pseudodistância é mais utilizada em posicionamentos com precisão de ordem métrica, pois utiliza o código para determinar a distância entre o satélite e o receptor. Desta forma, segundo Krueger (1996) e Monico (2008), os métodos de posicionamento podem ser classificados em:

- Absoluto - quando as coordenadas estão associadas diretamente ao geocentro;

- Relativo - o vetor formado entre as estações base e móvel é calculado, possibilitando a determinação das coordenadas desta estação que estão atreladas a um referencial materializado por um ou mais vértices de coordenadas conhecidas; e

- Diferencial - as coordenadas da estação móvel são calculadas com o emprego das correções diferenciais geradas na estação de referência, sendo que estas correções podem ser enviadas por um meio de comunicação para a estação móvel, neste caso as coordenadas são determinadas em tempo real. 


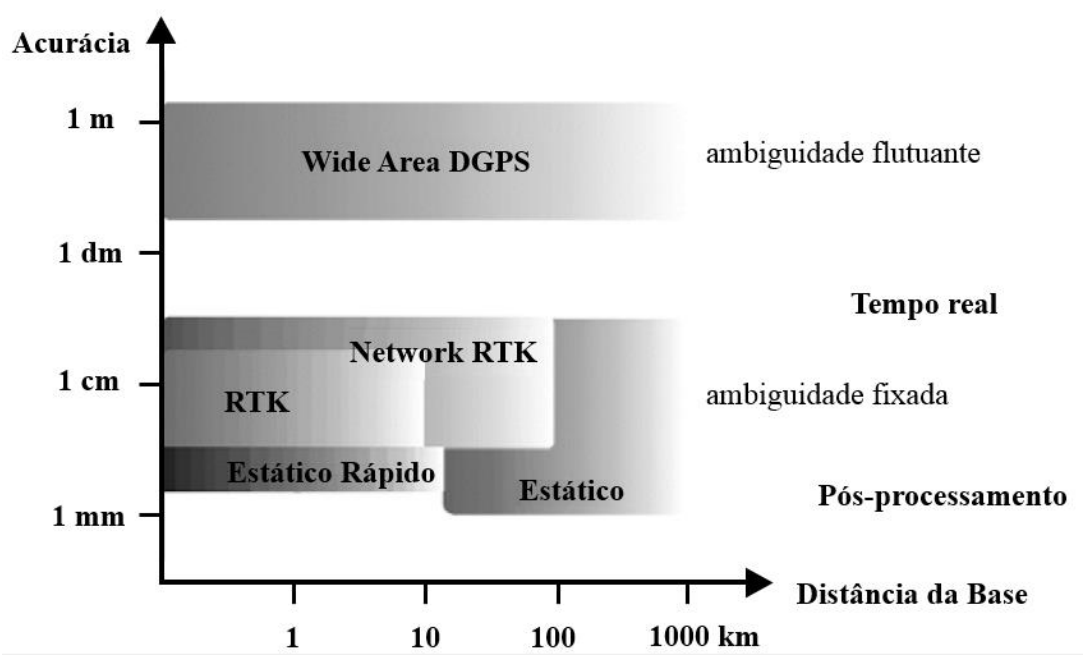

Figura 2: Precisão dependente da distância em relação a base para os diferentes métodos de posicionamento.

Fonte: Adaptado de Willgalis et al (2003).

O método absoluto, também é denominado na literatura de posicionamento por ponto ou isolado, pode ser realizado com as técnicas estática (antena estática) ou cinemática (antena em movimento). Caracteriza-se pela adoção de apenas um receptor visando à determinação das coordenadas de um ponto $(\phi, \lambda, \mathrm{h}$ ou $\mathrm{X}, \mathrm{Y}, \mathrm{Z})$ sobre a superfície terrestre, referidas ao sistema de referência vinculado ao sistema de posicionamento por satélites. Para o GPS, por exemplo, é adotado o WGS-84 (G1674) (World Geodetic System, 1984: refinado para a semana GPS 1674) (KRUEGER, 2006; NGA, 2012). Em geral este método possibilita a determinação destas coordenadas em tempo real sendo então denominado de Posicionamento por Ponto (PP), em que normalmente são utilizados receptores de navegação, empregando-se para o cálculo da posição de pontos sobre a superfície terrestre, geralmente, a pseudodistância derivada do código C/A presente na portadora L1 e a mensagem de navegação. No Serviço de Posicionamento Padrão (SPS), as precisões planimétricas alcançadas são de aproximadamente 13 metros e 25 metros (95\%), horizontal e vertical, respectivamente (Seeber, 2003).

O Posicionamento por Ponto Preciso (PPP) utiliza os dados coletados pelo método absoluto, contudo existe o processamento dos dados coletados (códigos e fase das ondas portadoras) por receptores de uma ou duas frequências, empregando correções para os relógios dos satélites e as efemérides precisas, informações produzidas e disponibilizadas pelo IGS (International GNSS Service) e por centros associados por meio de programas. Os dados podem ser processados por diferentes centros como AUSPOS (Australian Surveying and Land Information Group's Online GPS Processing Service) do Departamento de Recursos, Energia e Turismo da Austrália; CSRSPPP (Canadian Spatial Reference System) desenvolvido pela divisão de levantamento geodésico da NRCan (Natural Resources of Canada) e IBGE-PPP do Instituto Brasileiro de Geografia e Estatística (IBGE), o qual faz uso do serviço online de processamento desenvolvido pela NRCan, como descrito no Manual do Usuário: Aplicativo Online do IBGE-PPP (2013). Segundo Mayer \& Fuhrmann (2008) estes serviços têm como vantagens: reduções de custos, processamento automatizado, uso total e automático dos programas do International GNSS Service (IGS), uso global, economia de tempo e centímetros de precisão (usando as observações da fase da onda portadora, e resolução das ambiguidades).

O método de posicionamento relativo cinemático, proporciona uma precisão na ordem centimétrica (1 a $10 \mathrm{ppm}$ ), e consiste em se determinar uma coordenada para cada época de observação, onde um receptor ocupa a estação base enquanto o outro se desloca sobre as feições de interesse. Portanto, neste método, embora a antena esteja em movimento, a trajetória é descrita 
por uma série de pontos. Isso tem como consequência a necessidade do usuário dispor de no mínimo cinco satélites, para que haja a redundância e a solução seja passível de ser obtida (MONICO, 2008 e IBGE, 2008). Neste método é importante realizar uma inicialização, em que o receptor móvel permaneça estacionado por alguns minutos num ponto qualquer antes de percorrer a trajetória a ser descrita.

O posicionamento pelo Differential GPS (DGPS), atualmente, baseia-se na transmissão instantânea de dados de correções diferenciais dos sinais de satélites observados (pseudodistância ou fase da onda portadora), do receptor instalado na estação de referência ao receptor que percorre os vértices de interesse ou a trajetória a ser descrita, por um meio de comunicação. Desta forma, proporciona o conhecimento instantâneo de coordenadas precisas dos vértices ocupados e das trajetórias percorridas (INCRA, 2013). Quando estas posições instantâneas derivam das correções diferenciais obtidas com o emprego do código e código suavizado pela fase da onda portadora, denomina-se o método de DGPS e quando são obtidas por meio da fase da onda portadora de Real Time Kinematic (RTK). Estes métodos também diferem quanto à precisão alcançada, conforme Figura 2. Para o RTK, os dados de correção diferenciais são transmitidos por meio de um enlance de rádio instalado nas estações de referência e móvel, na qual se observa que para distâncias de até $10 \mathrm{~km}$ a precisão é inferior a alguns centímetros.

\section{Metodologia}

O DGPS/RTK é composto de uma estação de referência, uma estação móvel e um sistema de comunicação. A estação de referência modelo Leica GPS1200 foi instalada nas imediações da barragem, marco MSC04, configurado para sistema de referência SIRGAS 2000 para o levantamento realizado no dia 01 de dezembro de 2012 (Figura 3), onde sua localização foi escolhida buscando-se um maior alcance na transmissão das correções diferenciais devido às obstruções existentes na área. A estação móvel consistiu na embarcação empregada e o sistema de comunicação, formado por um par de rádios da Pacific Crest, operando na faixa de UHF, os quais permitem receber ou transmitir mensagens no formato RTCM (Radio Technical Commission for Maritime Services).

O posicionamento ocorreu em tempo real. Contudo, os dados brutos enviados pelos satélites da constelação GPS também foram armazenados com intervalo de 1 segundo na memória dos receptores da estação de referência e na estação móvel. Foi necessária a transformação do arquivo NMEA-0183 para o formato .txt. Posteriormente, devido à superabundância de coordenadas para um mesmo ponto, antes de qualquer análise foi realizada uma filtragem por uma rotina desenvolvida no Matlab, onde o programa selecionou a menor altitude caso houvesse mais de um valor para a mesma coordenada planimétrica $(\mathrm{x}, \mathrm{y})$, proporcionando desta forma um erro sistemático, evitando a aleatoriedade.

Visando uma análise da precisão e acurácia dos métodos de posicionamento planimétrico empregados na embarcação (DGPS/RTK, MPRC e PPP, no sistema de referência SIRGAS 2000 época 2000.4) foram selecionados os dados levantados no dia 01 de dezembro de 2012. A Figura 3 apresenta a trajetória descrita pela embarcação neste dia, bem como a localização da estação base (MSC04) para o posicionamento relativo cinemático, DGPS/RTK e o contorno do reservatório. Desta forma foi necessário efetuar uma nova seleção da trajetória da embarcação obtida pelo DGPS/RTK, em que foram empregadas as informações contidas na mensagem NMEA-0183 para o levantamento (Figura 3). Estas informações devem representar praticamente 
a mesma trajetória da embarcação obtida a partir do processamento dos dados coletados pelo método relativo cinemático.

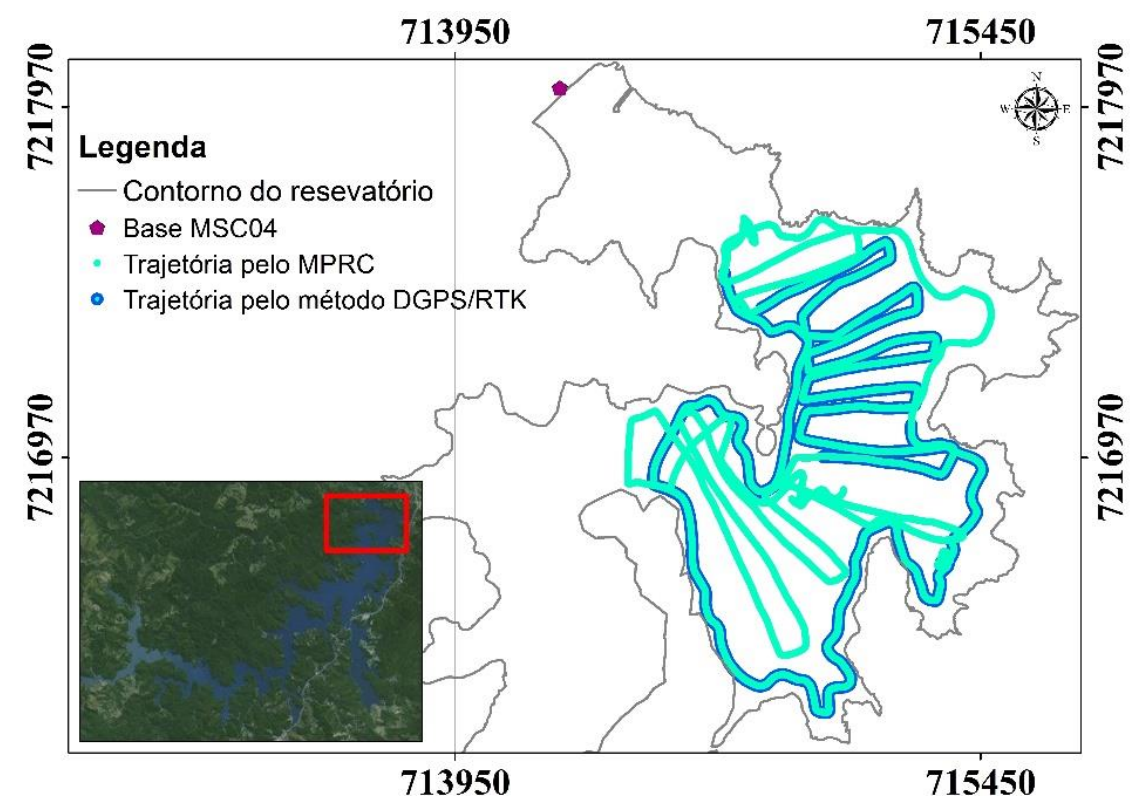

Figura 3: Localização da base MSC04 e linhas das trajetórias do levantamento batimétrico realizado em 01/12/2012 pelos métodos DGPS/RTK e MPRC. Coordenadas em metros, projeção UTM: Sistema de Referência SIRGAS 2000, zona 22S.

Fonte: Base de dados de Hilgert (2014).

Observa-se que não há um perfeito sincronismo entre as informações, devido ao intervalo de tempo que o computador leva para armazenar os dados; contudo a defasagem de tempo é menor que um segundo, não sendo significativa na análise em questão. Vale ressaltar que a trajetória obtida pelo MPRC é tomada como referência para a análise da acurácia do método DGPS/RTK e do PPP. Na Figura 3 observa-se a trajetória selecionada da mensagem NMEA-0183 (DGPS/RTK) que irá proporcionar a comparação entre os métodos (MPRC e PPP).

\subsection{Análise do posicionamento da embarcação}

Aplicou-se o cálculo das diferenças das coordenadas, em metros e projeção UTM, obtidas pelo processamento IBGE-PPP subtraídas das coordenadas processadas através do software Leica Geo Office 7.0 (LGO), considerada como referência. Desta forma, foram determinadas as discrepâncias, para os métodos PPP e DGPS/RTK em relação ao MPRC, nas componentes Estes $\left(\Delta \mathrm{E}_{\mathrm{j}}\right)$ e o Norte $\left(\Delta \mathrm{N}_{\mathrm{j}}\right)$, e planimétrica $\left(\mathrm{D}_{\mathrm{plan}, \mathrm{j}}\right)$ apresentadas nas equações (1), (2) e (3), respectivamente.

$$
\begin{aligned}
& \Delta \mathrm{E}_{\mathrm{j}}=\mathrm{E}_{\mathrm{k}, \mathrm{j}}-\mathrm{E}_{\text {pos }, \mathrm{j}} \\
& \Delta \mathrm{N}_{\mathrm{j}}=\mathrm{N}_{\mathrm{k}, \mathrm{j}}-\mathrm{N}_{\text {pos }, \mathrm{j}}
\end{aligned}
$$

Onde:

Índice $j$ indica a época GPS e $k$ é o método que será analisado;

$\Delta \mathrm{E}_{\mathrm{j}}$ : Discrepância entre as componentes Este dos métodos PPP e MPRC (metros);

$\Delta \mathrm{N}_{\mathrm{j}}$ : Discrepância entre as componentes Norte dos métodos PPP e MPRC (metros); 
$\mathrm{E}_{\mathrm{k}, \mathrm{j}}$; $\mathrm{N}_{\mathrm{k}, \mathrm{j}}$ : Componentes Este e Norte, respectivamente, obtidas pelo método a ser analisado (metros); e

$E_{\mathrm{pos}, \mathrm{j}} ; \mathrm{N}_{\mathrm{pos}, \mathrm{j}}$ : Componentes Este e Norte, respectivamente, obtidas pelo MPRC (metros).

$$
\mathrm{D}_{\text {plan }, \mathrm{j}}=\sqrt{\Delta \mathrm{E}_{\mathrm{j}}^{2}+\Delta \mathrm{N}_{\mathrm{j}}^{2}}
$$

Posteriormente foi calculado, de acordo com o manual da NSDI (1998), o erro médio quadrado $\left(\mathrm{RSME}_{\mathrm{i}}\right.$ ) nas componentes x e y para os métodos PPP e DGPS/RTK apresentado equação (4); e a acurácia planimétrica (RMSE plan), de acordo com a equação (5).

$$
\operatorname{RMSE}_{\mathrm{i}}=\sqrt{\frac{\sum\left(\mathrm{i}_{\mathrm{k}, \mathrm{j}}-\mathrm{i}_{\mathrm{pos}, \mathrm{j}}\right)^{2}}{\mathrm{n}}}
$$

Onde $i$ é o índice que varia nas componentes das direções x e y, $j$ é a época GPS, $k$ é o método que será analisado e $n$ é o número total de observações.

$$
\operatorname{RMSE}_{\text {plan }}=\sqrt{\operatorname{RMSE}_{\mathrm{X}}^{2}+\mathrm{RMSE}_{\mathrm{y}}^{2}}
$$

Mediante a aplicação dessas equações procede-se a análise planimétrica do posicionamento da embarcação.

\subsection{Análise dos parâmentros definidores da qualidade do posicionamento da embarcação}

Com o intuito de verificar a distribuição espacial dos parâmetros definidores da qualidade do posicionamento da embarcação (como resolução das ambiguidades, PDOP e número de satélites), obtidas na mensagem NMEA-0183, testaram-se diferentes métodos de interpolação como Kriging, Natural Neighbor, Spline e Inverse Distance Weight (IDW), disponibilizados no software ArcGIS ${ }^{1}$ 10.1, para área de pontos ao longo do reservatório.

\section{Resultados E Discussões}

\subsection{Posicionamento da embarcação pelo Método Relativo Cinemático}

Os dados gravados nas memórias dos receptores instalados nas estações de referência (marco MSC04) e móvel (embarcação), no dia 01 de dezembro de 2012, foram processados pelo software LGO. As coordenadas planimétricas que compõem esta trajetória advêm de uma solução de $100 \%$ dos inteiros das ambiguidades. Em relação à qualidade do posicionamento planimétrico do método de Posicionamento Relativo Cinemático, apresentada no LGO os valores mínimo e máximo foram de 0,001 e 0,050 metros, respectivamente. Com uma qualidade entre 0,004 metros e 0,009 metros em 10.772 pontos dos 17.047 que compõem a trajetória processada no levantamento (Figura 4). 


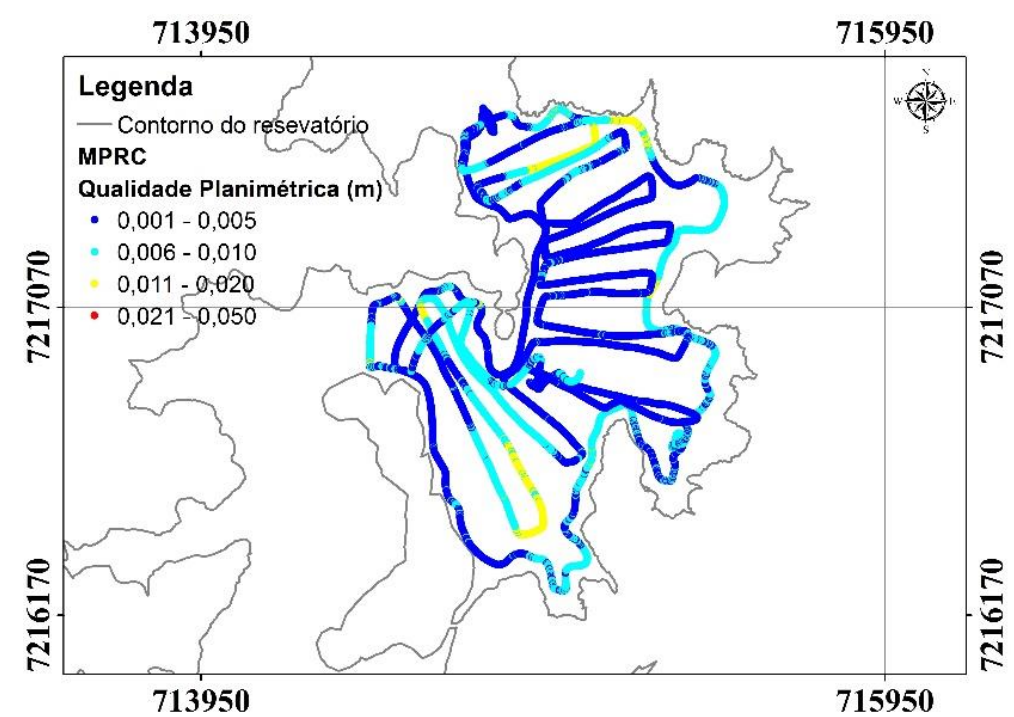

Figura 4: Qualidade do posicionamento planimétrico através do processamento dos dados levantados a partir do MPRC referente ao dia 01/12/12. Coordenadas em metros, projeção UTM: Sistema de Referência SIRGAS 2000, zona 22S.

A Figura 5 apresenta os desvios padrão obtidos para as coordenadas planimétricas, ou seja, os valores encontrados indicam a precisão relativa da trajetória descrita pela embarcação após o processamento. Constata-se que o resultado está dentro do esperado para este método de posicionamento, visto que o IBGE preconiza uma precisão de 1 a $10 \mathrm{ppm}$. Sendo esta trajetória descrita, tomada como referência para comparação entre aquelas advindas do PPP e do DGPS/RTK.

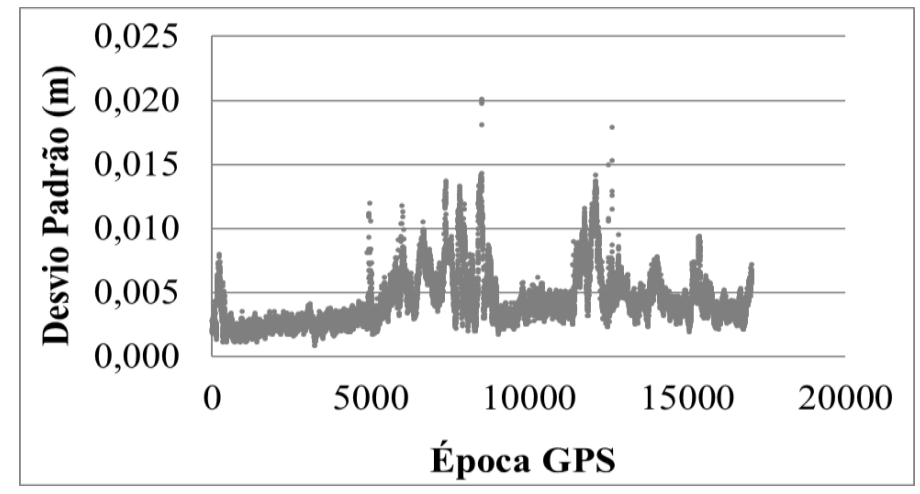

Figura 5: Gráfico dos desvios padrão do posicionamento planimétrico da embarcação obtido com o pós-processamento (MPRC).

\subsection{Posicionamento da embarcação através do método PPP}

Os desvios padrão para coordenadas planimétricas do PPP encontraram-se no intervalo entre 0,623 e 9,745 metros. Os maiores valores ocorreram da época inicial até a época 1.741 , período correspondente aos primeiros 29 minutos de observação, com registro a cada segundo. O método do IBGE-PPP para realizar o ajustamento sequencial e convergir à solução necessita um tempo de aproximadamente 30 minutos, fazendo com que as épocas iniciais, tenham como consequência, desvios padrão mais elevados (Bisbath \& Gao, 2008 apud KLEIN et al.,2010). Este fato decorre de que a solução gerada usa a combinação livre dos efeitos ionosféricos de primeira ordem (ionofree) (IBGE, 2013). 
Portanto, removendo os pontos referentes aos primeiros 30 minutos é possível verificar que o desvio padrão se encontra entre os valores mínimo e máximo de 0,06 metros e 0,13 metros, respectivamente (Figura 6). Neste caso a imprecisão da trajetória da embarcação seria inferior a $13 \mathrm{~cm}$, sendo superior àquela obtida com o MPRC. Pelo exposto anteriormente quando o usuário desejar empregar o PPP é conveniente que seja efetuada uma inicialização com a embarcação atracada ou docada de aproximadamente 30 minutos.

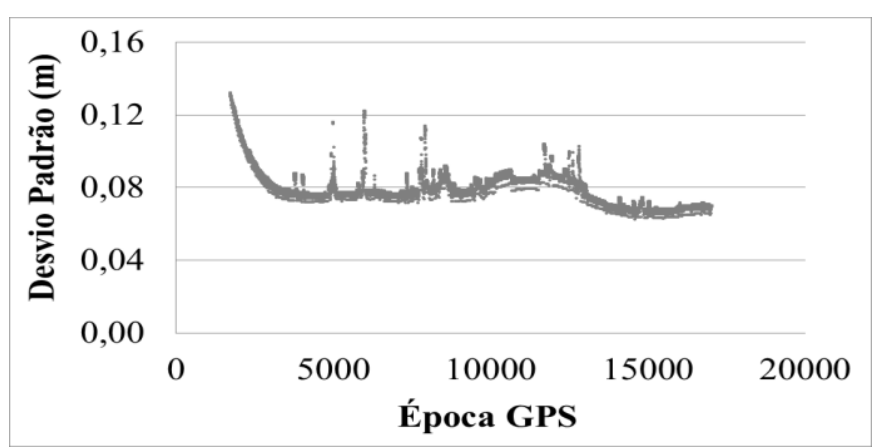

Figura 6: Gráfico do desvio padrão do posicionamento planimétrico com o uso do PPP com a exclusão dos primeiros 30 minutos utilizados na convergência da solução.

A Figura 7 apresenta as trajetórias descritas pela embarcação obtidas com base nos métodos MPRC e PPP, com uma discrepância máxima na componente $\mathrm{N}$ de aproximadamente $50 \mathrm{~cm}$ e $37 \mathrm{~cm}$ na componente E.

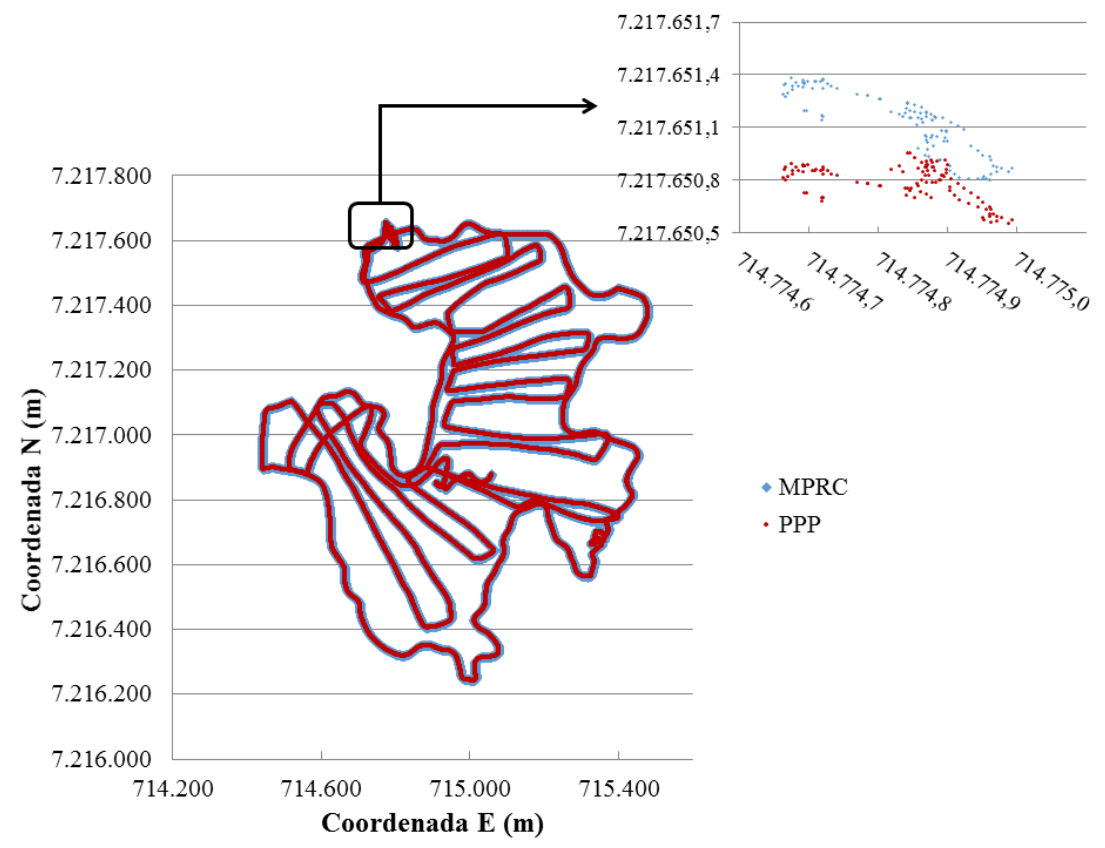

Figura 7: Trajetórias descritas pela embarcação pelo MPRC e PPP no dia 01/12/2012. Coordenadas em metros, projeção UTM: Sistema de Referência SIRGAS2000.

É possível verificar, visualmente, que a trajetória obtida com o processamento IBGE-PPP foi eficaz comparando com o método de referência adotado (MPRC). As discrepâncias para as componentes Norte e Este foram na ordem de decímetros, conforme ilustra a Figura 8A. Para a coordenada Este a discrepância foi entre o intervalo mínimo e máximo de -0,375 e 0,147 metros; e para a coordenada Norte, entre o intervalo mínimo e máximo de 0,108 e 0,507 metros, respectivamente. 


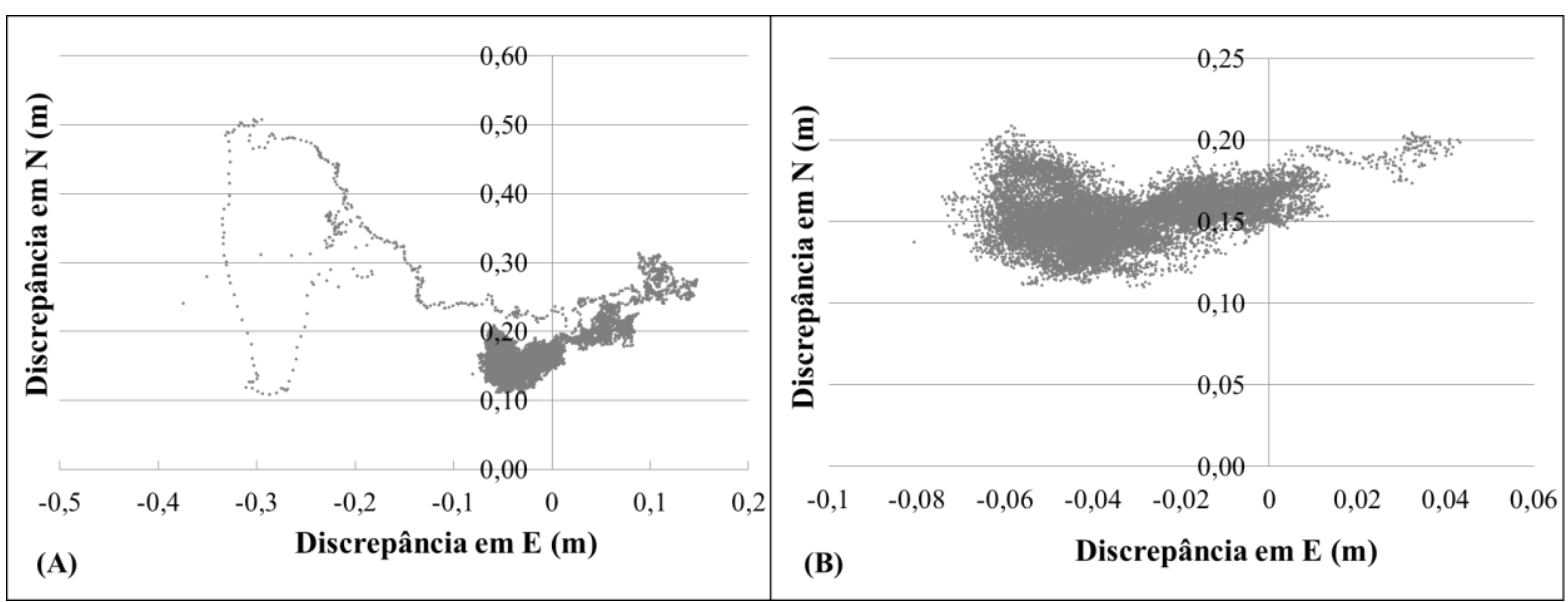

Figura 8: (A) Gráfico das discrepâncias para as componentes $\mathrm{E}$ e N, entre as trajetórias dos métodos MPRC e PPP. (B) Gráfico das diferenças planimétricas entre pós-processado (MPRC) e PPP com exclusão do tempo de convergência.

Visando detalhar mais as análises, os 30 minutos iniciais foram excluídos das trajetórias descritas e recalculando as diferenças planimétricas entre estas trajetórias verifica-se que elas se encontram entre -0,080 e 0,109 metros na direção E, e entre 0,043 e 0,208 metros na direção N (Figura 8B). Desta forma, se respeitada à inicialização de aproximadamente 30 minutos, pode-se dizer que a acurácia do método PPP deverá ser inferior a cerca de $25 \mathrm{~cm}$, para este caso.

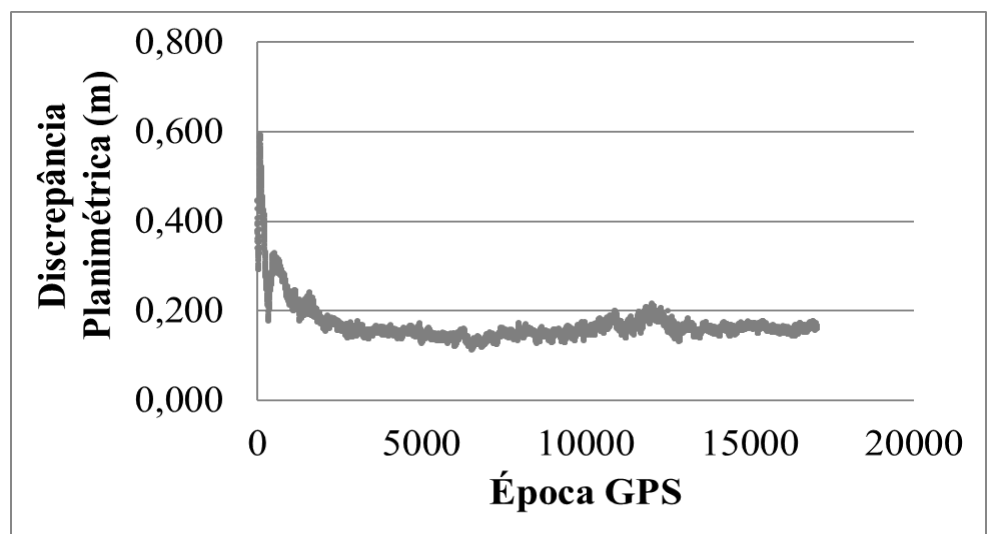

Figura 9: Gráfico da discrepância planimétrica entre as coordenadas do pós-processado (MPRC) e do PPP.

No cálculo da discrepância entre as coordenadas planimétricas obtidas com o pós-processamento (MPRC) e aquelas advindas do PPP, os valores variaram entre 0,113 e 0,593 metros, com um valor médio de 0,169 metros para um conjunto de um total de 17.047 épocas GPS (Figura 9). A partir do cálculo do erro médio quadrático observou-se que o ${ }^{R M S E} E_{x}$ foi menor que ${ }^{R M S E_{y}}$, os quais apresentaram valores de 0,053 m e 0,167 m, respectivamente. Esses resultados geraram um RMSE $_{\text {plan de }} 0,175$ metros entre os métodos PPP e MPRC, ou seja, a acurácia da trajetória descrita pela embarcação pelo PPP é da ordem de decímetros quando consideradas todas as épocas de observação. 


\subsection{Posicionamento da embarcação com DGPS/RTK}

Os dados deste levantamento foram disponibilizados no formato .txt, arquivo NMEA-0183, com mensagens do tipo GGK.

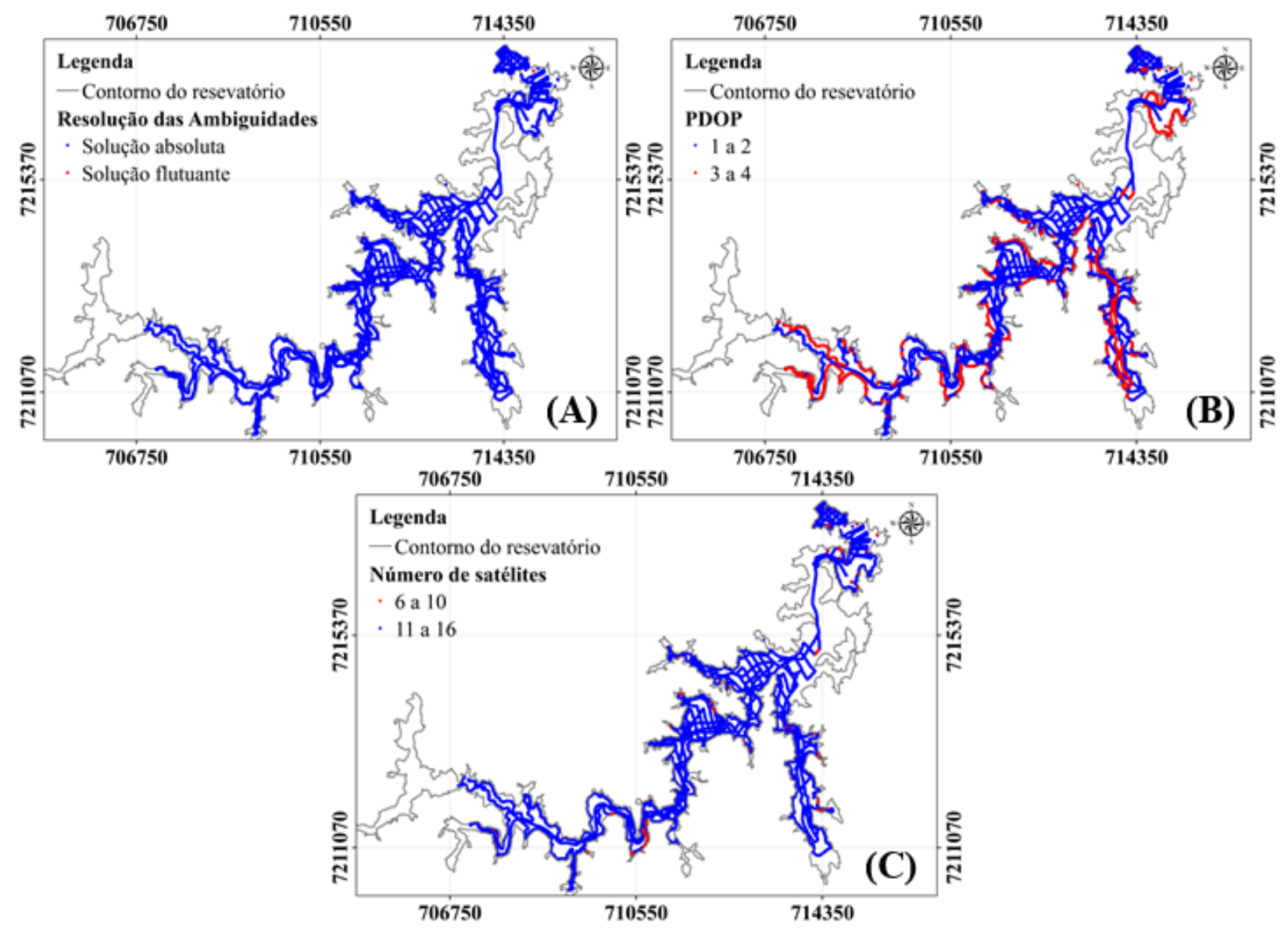

Figura 10: (A) Mapa da distribuição espacial da resolução das ambiguidades. (B) Mapa da distribuição espacial do PDOP. (C) Mapa da distribuição espacial do número de satélites. Coordenadas em metros, projeção UTM: Sistema de Referência SIRGAS 2000, zona 22S.

Os maiores valores de PDOP encontram-se próximos às margens do reservatório. Porém, para todos os pontos o PDOD se manteve abaixo de 5 (Figura 10B), em que de acordo com a literatura consultada é um valor inferior ao almejado (menor que 6). O número de satélites observados foi superior ao mínimo necessário em todo o levantamento, variando entre 6 e 16 satélites (Figura 10C). Na maioria dos pontos o número de satélites observados foi superior a 11. Analisando a Figura 10C constata-se, visualmente, que os pontos onde há um menor número de satélites estão situados às margens do reservatório. Locais estes que sofrem a influência da vegetação presente no entorno da trajetória descrita pela embarcação. 


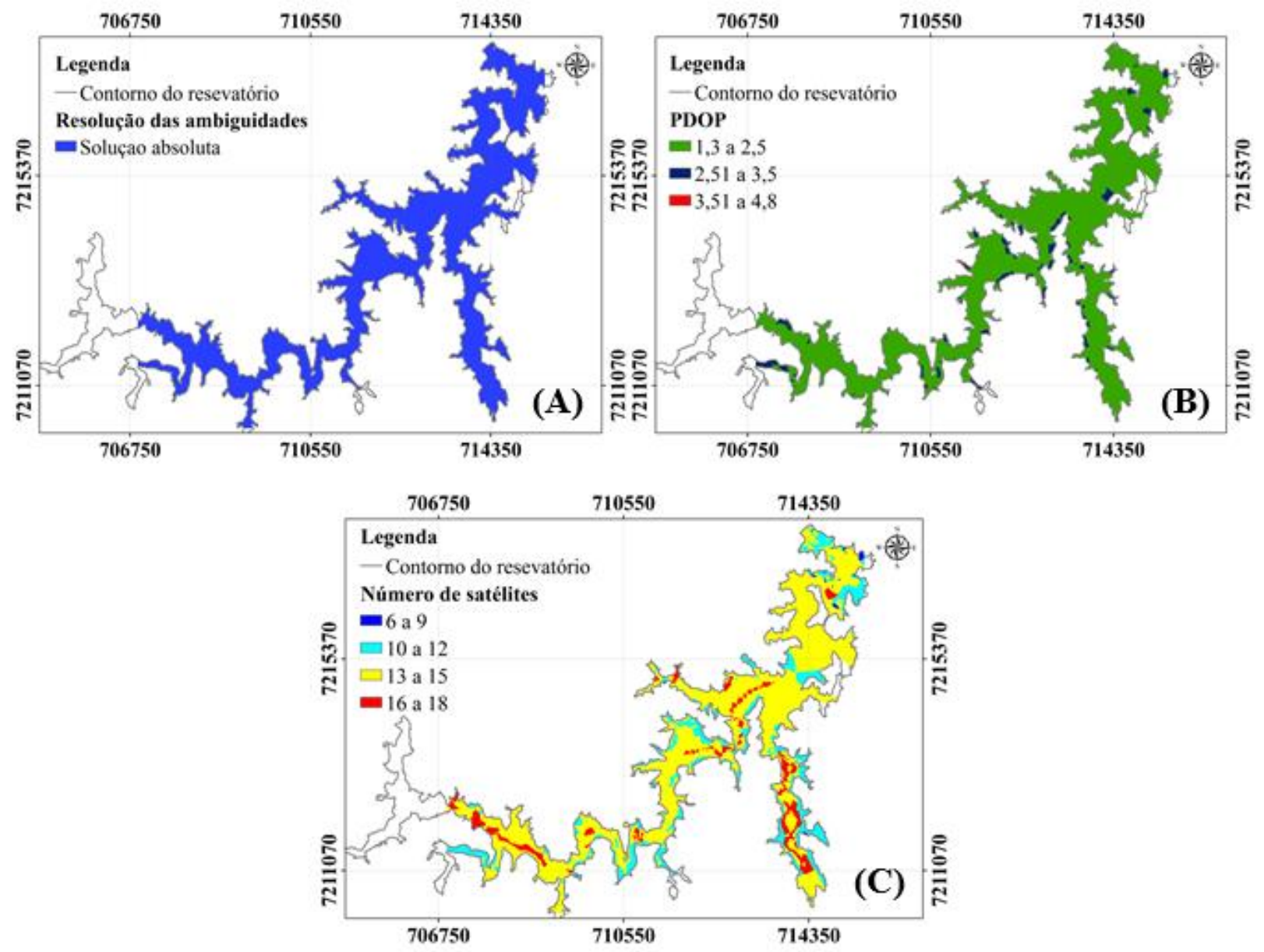

Figura 11: (A) Mapa da distribuição espacial da resolução das ambiguidades. (B) Mapa da interpolação referente aos valores de PDOP durante o levantamento. (C) Mapa da interpolação referente ao número de satélites observados durante o levantamento batimétrico. Coordenadas em metros, projeção UTM: Sistema de Referência SIRGAS 2000, zona 22S.

Para estimar a resolução das ambiguidades, o número de satélites e PDOP; foi utilizado o interpolador IDW, o qual melhor representou as características do reservatório. Pois devido à heterogeneidade na dispersão dos pontos, os outros métodos generalizaram as informações, representando de forma inadequada à realidade dessas variáveis ao longo da área de estudo. A resolução das ambiguidades (Figura 11A) apresentou uma solução absoluta para todo o reservatório. O número de satélites observados foi de 6 a 18, com o predomínio de 13 a 15 satélites observados na maior parte do levantamento (Figura 11C). O intervalo de PDOP (Figura 11B) ficou entre 1,3 e 4,8, com predominância de valores mais baixos (1,3 a 2,5), e os valores mais elevados foram identificados nas bordas do reservatório. Segundo Krueger (2011), para o método cinemático os valores obtidos neste trabalho estão dentro da classificação de um bom levantamento, ou seja, apresentam PDOP menor que 5.

A partir da distribuição dos valores de PDOP e número de satélites, é possível verificar um padrão, em que nas regiões onde há presença de um número menor de satélites os valores de PDOP são superiores em relação aos pontos em que há um maior número de satélites. Este fato justifica-se devido ao PDOP estar diretamente ligado a geometria dos satélites, claramente observado. 


\section{4 . Comparação entre os posicionamentos pelo MPRC e DGPS/RTK}

As discrepâncias nas componentes $\mathrm{E}$ e $\mathrm{N}$, apresentaram valores médios de -1,53 e 1,29 metros, respectivamente. Com variação entre $-3,30 \mathrm{~m}$ e $1,50 \mathrm{~m}$ para a componente $\mathrm{E}$; e de $-1,17 \mathrm{~m}$ a 2,89m para N (Figura 12).

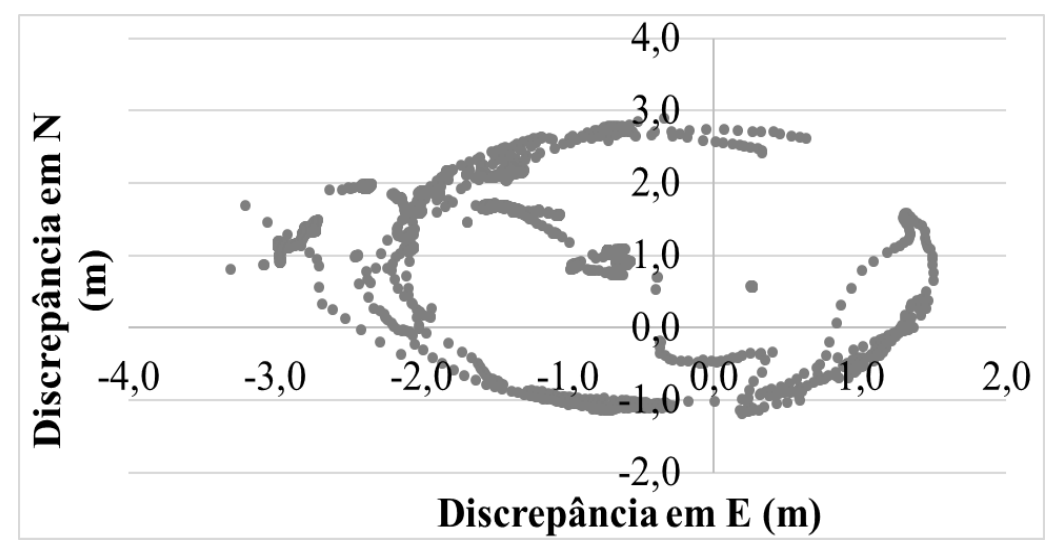

Figura 12: Gráfico das discrepâncias para as componentes E e N, entre as trajetórias dos métodos MPRC e DGPS/RTK.

A partir desses valores se obteve a discrepância planimétrica com intervalo entre 0,41 e 3,62 metros. Com o uso do MPRC como referência esta operação envolveu 4.318 observações, a qual gerou resultados na ordem do metro, como observado na Figura 13.

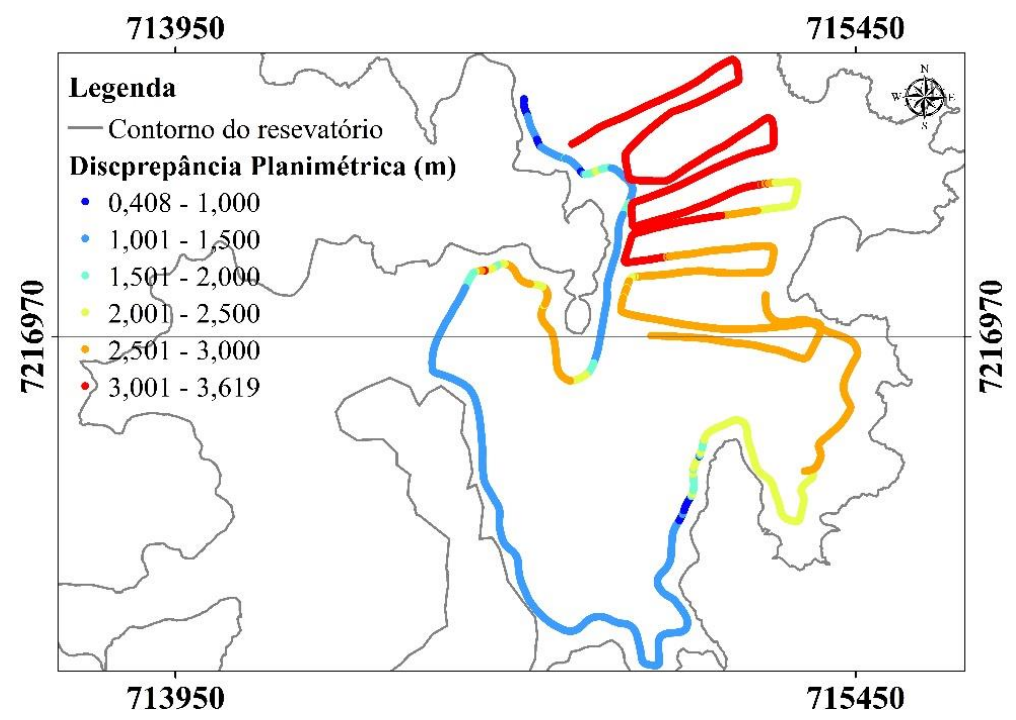

Figura 13: Distribuição da discrepância planimétrica entre as coordenadas dos métodos DGPS/RTK e MPRC. Coordenadas em metros, projeção UTM: Sistema de Referência, SIRGAS 2000, zona $22 \mathrm{~S}$.

Essa diferença pode estar atrelada ao erro no momento da filtragem dos pontos, visto que esta foi feita de forma visual devido à falta de uma variável em comum que pudesse servir de ligação entre as duas planilhas de informações. No entanto, apesar do receptor estar configurado para RTK, de acordo com a Figura 11A, as soluções são provenientes de um método absoluto. Podendo proporcionar precisões planimétricas de até 12 metros (95\% de probabilidade) (Krueger, 2006). 
Mediante o cálculo do erro médio quadrático observou-se que o ${ }^{R M S E} x_{x}$ foi maior que ${ }^{R M S E} y_{o s}$ quais apresentaram valores de 1,817 m e 1,539 m, respectivamente. Esses resultados geraram um

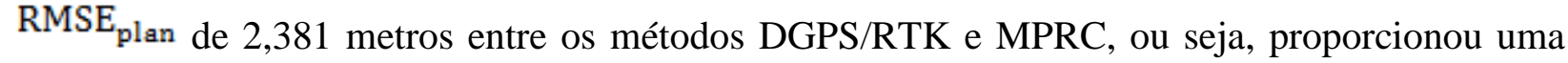
acurácia na ordem de metros.

\section{Conclusão}

Analisando os métodos de acordo com a resolução da ANA (2013), a qual preconiza uma precisão planimétrica de 2 a 5 metros, para o DGPS/RTK é possível utilizar a qualidade planimétrica extraída do LGO. O PPP poderia ser aplicado desde que desconsiderados os 30 minutos iniciais, ou seja, é imprescindível a inicialização do equipamento com a embarcação docada; e o MPRC/RTK atende totalmente as exigências. Comparando os três métodos, o DGPS/RTK é o mais prático e viável, pois proporciona a correção em tempo real da posição da embarcação sincronizada com a profundidade. No entanto, caso o usuário não tenha a sua disposição um RTK, é indicado realizar o levantamento com o GPS através do método cinemático, posteriormente enviar os dados para o serviço online do IBGE-PPP e utilizar as informações processadas por esse serviço (devido a este método ter apresentado resultados condizentes com a precisão esperada e não exigir alto custo financeiro).

\section{REFERÊNCIAS}

ANA - Agência Nacional de Águas (Brasil). Orientações para atualização das curvas cota $x$ área x volume. Brasília: ANA, SGH, 2013. 40 p.

BRASIL. Resolução Conjunta $n^{\circ}$ 3, de 10 de agostos de 2010. Diário Oficial da República Federativa do Brasil. Brasília, DF, seção 1, v. 147, n. 201, p. 124,20 de outubro de 2010. http://arquivos.ana.gov.br/infohidrologicas/cadastro/ResolucaoConjunta_n_003-2010.pdf

Carvalho, G. F.; Kan, A.; Ferreira, R. S.; Da Silva, E. D.; Gibertoni, R. F. C. Avaliação da concentração de metano no Reservatório de Capivari. XVIII Simpósio Brasileiro de Recursos Hídricos. 2009.

Ceylan, A.; Ekizogllu, I. A Study on The Assessment of Bathymetric Changes Via GIS: Altinapa Dam (Konya) Example. FIG Working Week 2012. Knowing to manage the territory, protect the environment, evaluate the cultural heritage. Rome, Italy, 6-10 May 2012. Rome, Italy, 6-10 May 2012

COPEL. Usina Parigot de Souza: Informações técnicas. 2011. http://www.copel.com/hpcopel/root/nivel2.jsp?endereco=\%2Fhpcopel\%2Froot\%2Fpagcopel2.ns f\%2F044b34faa7cc1143032570bd0059aa29\%2F08013ddc621f4eed03257412005ed73b.

FCMC - Fórum Capixaba de Mudanças Climáticas e Uso Racional da Água. Energia Hídrica Elétrica. 2014. http://www.fcmc.es.gov.br/download/energia_hidricaeletrica.pdf.

Hilgert, S. Analysis of spatial and temporal heterogeneities of methane emissions of reservoirs by correlating hidro-acoustic with sediment parameters. Submitted in Partial Fulfillment of the Requirements for the Degree of DOCTOR OF ENGINEERING - Department of Civil 
Engineering, Geo and Environmental Sciences, Karlsruhe Institute of Technology - KIT, Karlsruhe, 2014.

IAP - Instituto Ambiental do Paraná. Reservatório do Capivari Variáveis. 2010. http://www.iap.pr.gov.br/arquivos/File/Monitoramento/monitoramento_qual_das_aguas/reserv_c apivari.pdf.

IBGE - Instituto Brasileiro de Geografia e Estatística. Recomendações para levantamentos relativos estáticos - GPS. 2008. http://www.inde.gov.br/images/inde/recom_gps_internet.pdf.

IBGE - Instituto Brasileiro de Geografia e Estatística. Manual do Usuário: Aplicativo Online IBGE-PPP. 2013. http://www.ibge.gov.br/home/geociencias/geodesia/ppp/manual_ppp.pdf.

INCRA - Instituto Nacional de Colonização e Reforma Agrária. Manual Técnico de Posicionamento: georreferenciamento de imóveis rurais. 1 ed. Brasília, 2013. http://www.incra.gov.br/sites/default/files/uploads/estrutura-fundiaria/regularizacaofundiaria/certificacao-de-imoveis-rurais/manual_tecnico_de_posicionamento_1_edicao.pdf

Klein, I.; Matsuoka, M.T.; De Souza, S. F. Análise do serviço on-line de PPP (GDGPS - APPS) para Receptores de Dupla Frequência: um estudo envolvendo dados de estações da RBMC. Journal of Geoscience. 6(2): 90-98, jul/dez 2010.

Krueger, C. P. Investigação sobre aplicações de alta precisão do GPS no âmbito marinho. Tese (Doutorado em Ciências Geodésicas) - Setor de Ciências da Terra, Universidade Federal do Paraná, Curitiba, 1996.

Krueger, C. P. Relatório apresentado a CAPES: Investigação de Fontes de Erros no posicionamento GPS e modelagem dos erros. Curitiba, 2006.

Krueger, C. P. Posicionamento por satélites: Métodos de Posicionamento. Laboratório de Geodésia Espacial e Hidrografia, Universidade Federal do Paraná, 2011. http://www.lage.ufpr.br/downloads/levgeod2/Parte6_metodos.pdf.

Mayer, M.; Fuhrmann, T. GPS vs. GNSS data processing on-line. Curitiba: PROBRAL Programa de Pós-Graduação em Ciências Geodésicas, Universidade Federal do Paraná e Geodetic Institut, Karlshure Universität, Agosto, 2008.

Monico, J. F. G. Posicionamento pelo GNSS: descrição, fundamentos e aplicações. 2 ed. São Paulo: Editora Unesp, 2008.

NSDI - National Spatial Data Infrastructure. Geospatial Positioning Accuracy Standards Part 3: National Standard for Spatial Data Accuracy. FGDC-STD-007.3-1998. https://www.fgdc.gov/standards/projects/accuracy/part3/chapter3

NGA - National Geospatial-Intelligence Agency. World Geodetic System 1984. 2012. http://www.unoosa.org/pdf/icg/2012/template/WGS_84.pdf

Seeber, G. Satellite Geodesy Satellite Geodesy: Foundations, Methods and Applications. 2 ed. Berlin. New York: Walter de Gruyter, 2003.

Willgalis, S.; Seeber, G.; Krueger, C. P. Romão, V. M. C. A real time GPS reference network for cadastral surveys in Recife, Brazil. Revista Brasileira de Cartografia, Rio de Janeiro, v. 15, n. 1, julho 2003. $\underline{\text { http://www.lsie.unb.br/rbc/index.php?journal=rbc\&page=article\&op=download\&path\%5B\%5D }}$ $=176 \&$ path $\% 5 \mathrm{~B} \% 5 \mathrm{D}=159$.

Recebido em 29 de junho de 2016.

Aceito em 2 de dezembro de 2016. 